\title{
HLA-A3 Positive Cells Present
}

National Cancer Institute

\section{Source}

National Cancer Institute. HLA-A3 Positive Cells Present. NCI Thesaurus. Code C69409.

A laboratory test result indicating the presence of HLA-A*03 positive cells in a tissue sample. 